\title{
Rapid prototyping and fast user trial of multimedia broadcast and cellular services
}

\author{
John Cosmas*, Leon Cruickshank, \\ Leina Elgohari, Takebumi Itagaki, Alan Lucas, \\ Kannan Krishnapillai and Lizhi Zheng
}

\author{
Email: john.cosmas@brunel.ac.uk \\ Email: leon.cruickshank@brunel.ac.uk \\ Email: leina.elgohari@brunel.ac.uk \\ Email: T.Itagaki@brunel.ac.uk \\ Email: alan.lucas@brunel.ac.uk \\ Email: kannan.krishnapillai@brunel.ac.uk \\ Email: Lizhi.Zheng@brunel.ac.uk \\ *Corresponding author
}

Brunel University, Uxbridge, Middlesex UB8 3PH, UK

\begin{abstract}
This paper presents the results of fast user trial of multimedia services that are enabled when a mobile terminal has access to converged services over digital broadcast and mobile telecommunications networks. It first describes the motivations behind developing this system and describes the service scenarios that benefit most from it. It then provides an overview of the service components of the test case scenario. Finally, it presents the results of fast user trials on end users of the services that were developed. This work was conducted as part of the EU-funded CISMUNDUS project.
\end{abstract}

Keywords: rapid prototype; fast user trial; broadcast and cellular service.

Reference to this paper should be made as follows: Cosmas, J., Cruickshank, L., Elgohari, L., Itagaki, T., Lucas, A., Krishnapillai, K. and Zheng, L. (2005) 'Rapid prototyping and fast user trial of multimedia broadcast and cellular services', Int. J. Mobile Communications, Vol. 3, No. 3, pp.263-286.

Biographical notes: John Cosmas obtained a BEng honours degree in Electronic Engineering at Liverpool University in 1978 and a PhD in Image Processing and Pattern Recognition at Imperial College in 1987. He is a Professor of Multimedia Systems and his research interests are concerned with the design and experimentation of new fourth-generation TV and telecommunications services and networks, multimedia content and databases, and video/image processing. He has contributed towards eight EEC research projects and has published over 80 papers in refereed proceedings and journals. He leads the Multimedia and Network Systems research group within the School of Engineering and Design at Brunel University.

Leon Cruickshank is a designer and lecturer with a background in the arts, in the School of Engineering at Brunel University. He works between and across boundaries and contributed to the DTI-funded NCTI multidisciplinary project with Bristol University the National Film and Television School and the University of the West of England. This project and the IST-funded CISMUNDUS project exploring the broadcast and Telco possibilities in mobile 
devices contributed to a $\mathrm{PhD}$ dissertation developing new symbiotic relationships between designers and users. Leon is also Art Director of BIT lab, Brunel's $£ 1.4$ million virtual reality, visualisation and grid computing facility.

Leina Elgohari obtained an HND in Graphic Design from the University of Hertforshire (1998) and a BSc honours degree in Multimedia Technology and Design from Brunel University in 2001 and was awarded an HSBC prize (2001). She has been working on her $\mathrm{PhD}$ research in the design of user interface specifically for interactive TV and PDA within the European-funded projects CISMUNDUS (Convergence of IP-based Services for Mobile Users and Networks in DVB-T and UMTS Systems) and SAVANT (Synchronised and Scalable AV content Across Networks).

Takebumi Itagaki obtained a BEng degree in Applied Physics at Waseda University in Tokyo (Japan), a Postgraduate Diploma in Music Information Technology at City University in London and a PhD at University of Durham with a dissertation "Real-time Sound Synthesis on a Multi-processor Platform" covered issues on DSP, distributed and parallel processing, and real-time sound synthesis. In 1998, he was appointed as a lecturer at Glasgow Caledonian University, thence in 2000 as a lecturer at Brunel University where he has been involving with EU-IST RTD Projects in multimedia and digital TV; 3D MURALE, SAMBITS, CISMUNDUS, SAVANT, CONFLUENT and INSTINCT.

Alan Lucas obtained a BEng honours degree in Computer Science at University of Glasgow in 2000 and has been conducting $\mathrm{PhD}$ research into terminal application architectures for converged broadcast and telecommunication services. He has contributed towards the EU-funded projects SAMBITS, CISMUNDUS, and INSTINCT.

Kannan Krishnapillai obtained a BEng honours degree in Electronic Engineering at Brunel University in 2000 and has been conducting PhD research into content and service description tools for converged broadcast and telecommunication services. He has contributed towards the EU-funded projects SAMBITS, CISMUNDUS, and INSTINCT.

Lizhi Zheng received his BS in Electronic Engineering from ShenZhen University, China in 1997 and his MS in Microelectronics and Telecommunication from Liverpool University, UK in 1998. He is currently a $\mathrm{PhD}$ candidate and also a research assistant working for the EU-funded project INSTINCT in the Department of Electronics and Computer Engineering, at Brunel University, UK. He has contributed towards the EU-funded projects CISMUNDUS and INSTINCT. His research interests are focused on parallel computing, video processing, converged broadcast and telecom service.

\section{Introduction}

The purpose of rapid prototyping of multimedia services is to demonstrate the viability and validity of service proposals without going through the huge effort of building delivery systems and end-user terminals and deploying services. This is a very important step towards service development because, first, it allows service designers to visualise how their proposals would look like on an end-user terminal to obtain a common 
understanding of the service concept and, second, it enables service designers to test the usefulness of their ideas on relevant user groups well before the completion of any delivery system and end-user terminal technology.

As new interactive multimedia services for digital TV services are a completely new concept, it is very hard to predict the consumer's behaviour to such applications particularly since network operators are still in the process of working out their business models for these services [1]. It is therefore unlikely that 'crisp and clear' user requirements will be drawn up for the development team and therefore it is necessary to apply an 'unconventional' project methodology, such as rapid application development or fast prototyping [2]. It is not enough to simply define the requirements of services [3] and hypothesise what impact new services concepts will have on users [4]. These need to be tested using fast prototyping and fast user trials using tools similar to those that are used for creating internet services [5]. Specialised rapid prototyping systems such as MediaBuilder platform fulfil this need for ATM services by offering rapid service creation and deployment through an extensible set of service components [6]. Service creation tools for intelligent networks used interactive visual programming for the composition of new services from service building blocks and the monitoring of their execution in the intelligent networks [7-8]. Rapid prototyping was also used to experiment with the options for TV-based services with interactive facilities [9]. It was used to find out how the test subjects reacted to tele-shopping and choice of camera angles for viewing football games.

This fast prototype approach towards developing services was used in the European Commission-funded research project CISMUNDUS (Convergence of IP-based Services for Mobile Users and Networks in DVB-T and UMTS Systems). This approach is different to the ones mentioned above because it uses common desktop publishing tools (Macromedia Director) to create the fast prototype simulation which has the advantage of being very well known in the graphics design industry and because it was used to develop and demonstrate the delivery and consumption of interactive multimedia services over a converged digital broadcast (DVB-T) and cellular (GPRS) system. The proposition is that users on the move will like to view streamed TV broadcast services enhanced with additional services that provide streamed and stored additional media. Since the main limitation to cell broadcast in both GPRS and UMTS networks is their relative low bit rate [10-11], the convergence of broadcast and cellular networks provides a low-cost approach to providing a high bandwidth multicast IP downlink that can be used for accessing multimedia services and is also able to provide complementary services and coverage over broadcast and cellular networks [12]. A complementary service delivers a high quality service on multicast IP over DVB if a large number of users subscribe to a given service and delivers an alternative quality service on unicast IP over cellular network if a few users subscribe. Complementary coverage continues to deliver a service with alternative quality using the GPRS network when there is no longer DVB-T coverage. A fast prototype was used to demonstrate what high bandwidth multicast downlink, complementary service, and complementary coverage service could look like.

The service scenarios that most benefit from converged broadcast and cellular systems are those that experience a large demand for a single service. Typically the service is associated with a large public event such as a pop concert, a sporting occasion, or an exhibition at a tourist attraction. A good example of this occurred during the Football World Cup (France '98) when over two million US football fans made hits on 
World Cup internet pages to access latest scores and textual commentary during matches because their national broadcasters were not providing live coverage of these matches [13]. In particular, there was a surge in the number of hits at the start of each match. A second example occurred during the Madonna pop concert in London when there were 90 million hits to access streamed low resolution audio-video of the concert [14]. It was claimed that nine million people were able to access the service.

Initially a number of service scenarios were considered and fully described, namely: tourist guide, live sports event, airport, and train travel. A number of different ergonomic user interfaces for the tourist guide and live sport services were built using quick prototyping tools. These tools simulated the functionality of the proposed service concepts and had the 'look and feel' of the proposed user interface. Early involvement of users checked the acceptability of the user interfaces using suitable user questionnaires. These users were from a young upwardly mobile, computer literate cross section of society. This provided guidance for designing the service scenario. The main criterion for selecting a service scenario was its ability to demonstrate usefulness of convergence of telecom and broadcast networks, to attract and engage users and to be demonstrated at exhibitions, such as IBC 2003. The service concept that was finally selected for demonstration in the CISMUNDUS project was centred on a live sports event.

\section{Service concept}

In order to demonstrate the type of real-time broadband service that could be delivered on IP over DVB, the scenario had to be a live broadcast. Since it was impossible to host a real live sports event during a CISMUNDUS demonstration it was decided to host a sports event based around an easily organised game of table football. With the table football service scenario, it was now possible to demonstrate real-time sports services such as Multi View Football. In this service, the viewer was given the choice of viewing different real-time views of the football game, namely: the main streamed audio/video programme view, an alternative streamed audio/video programme view on a different DVB PID, and an alternative streamed audio/video view on IP over DVB. With the table football service scenario, it was now possible to demonstrate services that provide different quality of service depending on the number of users that had subscribed such as Match Alerts service. In this service, an alternate quality of service was provided depending on the number of viewers who had chosen to subscribe to the service. If a few viewers had subscribed then a single GIF image was used to display the latest score in another football match. Otherwise if many viewers had subscribed then a video clip of the latest goal being scored in another football match was streamed. With the Match Alerts service, it was now also possible to demonstrate 'out of DVB area' service provisioning. If a viewer was watching the IP over DVB version of the Match Alerts service and wandered outside the DVB coverage area, then the service was resumed on the IP over GPRS version of the service.

Apart from streamed services on IP over DVB the system also demonstrated the operation of legacy services:

- Service with only DVB components - this was the standard DVB with MPEG2 audio/video accessed in the sports scenario from a programme selection interface. 
- $\quad$ Service with only IP components - this was the standard IP service demonstrated in the sports scenario by the Better Bets service.

- Service with dependent DVB and IP components - this was a DVB service with dependant IP service components that can be accessed on IP over GPRS and was demonstrated in the sports scenario by the Electronic Match Program service.

\subsection{Electronic Match Program (EMP)}

The EMP service offered the user access to a set of off line HTML pages that provided additional information about the current football game, as shown in Figure 1. This information included team formations, player information, previous results, and current league positions. The EMP service was a static service since the set of HTML pages did not change during the duration of the service. All required functions of this service were supported by the terminal including HTML player and FTP download mechanism. The service icon, description, and subscription acknowledgement fly-out is shown in Figure 2.

Figure 1 EMP internet pages

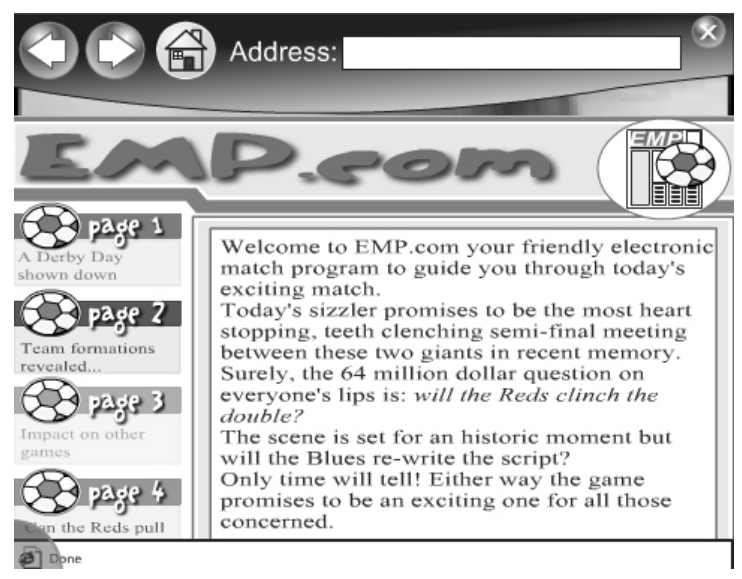

Figure 2 EMP service icon, description, acknowledgement
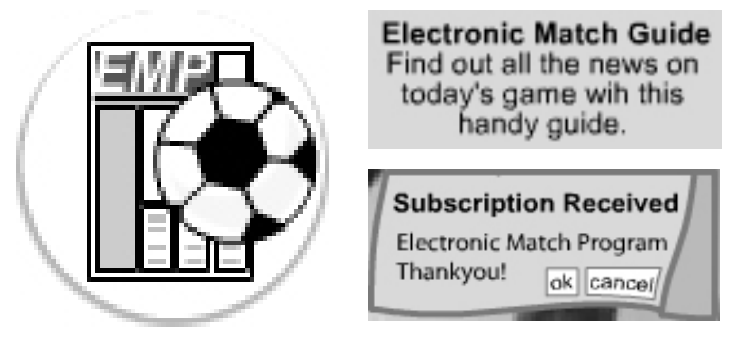


\subsection{Multiview Football (MVF)}

The MVF service offered the users a choice of camera angles of a football game. The angles offered included the public DVB MPEG-2 view that everyone had access to, an extra DVB MPEG-2 only accessible by subscribers of the MVF, and an IP MPEG-2 stream again only accessible by subscribed users. This service made use of video player client to run the service. The 'client side code' implemented its own control flow methods which were accessed by service user interface illustrated in Figure 3, allowing the switch of camera views depending on the user interaction with this service's front end. The service icon, description, and subscription acknowledgement fly-out is shown in Figure 4.

Figure 3 MVP controls

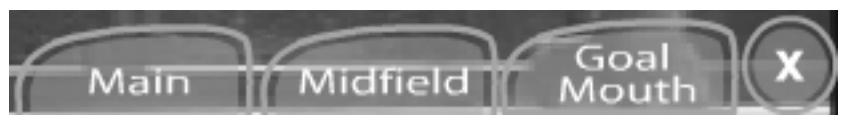

Figure 4 MVF service icon, description, acknowledgement
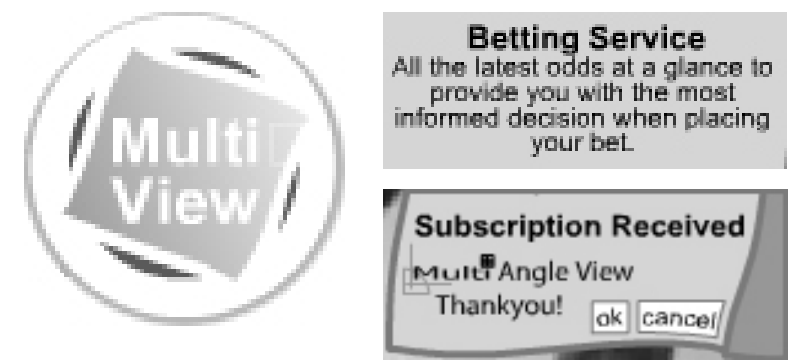

\subsection{Enhanced football Match Alert (MA)}

The Match Alert (MA) service presented the user with the opportunity to view MPEG-2 video clips of goals being scored in other games currently taking place. This service was an example of a nonsynchronised dynamic service where the service listens for goal events before downloading the video clip. The MA service used the FTP mechanisms to download the video clip, the location of which is known by the 'client side code'. This service used the Personal Video Recorder to start the video clip, as shown in Figure 7, once the user had selected the service icon of the Match Alert or an alternate version of the service, JPEG image as shown in Figure 6, if insufficient viewers have subscribed to this service. The 'client side code' also implemented the network manager service listener to receive service announcements. If a service was announced with the same service name as the MA service and contains a 'notification' as its media type, then this indicated that a goal has been scored and that the 'client side code' should download a video clip via FTP. The service icon, description, and subscription acknowledgement fly-out is shown in Figure 5. 
Figure 5 EF service icon, description, acknowledgement

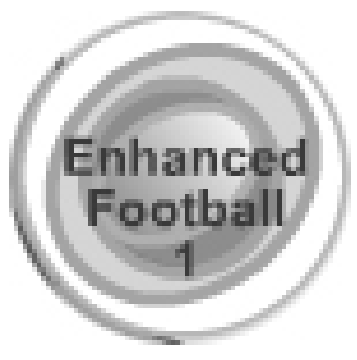

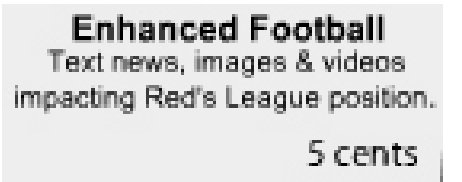

Payment Confirmation

QEnhanced Football

5 cents
Thankyou! ok cancel

Figure 6 Alternate quality image of latest result



Figure 7 Video clip of goal

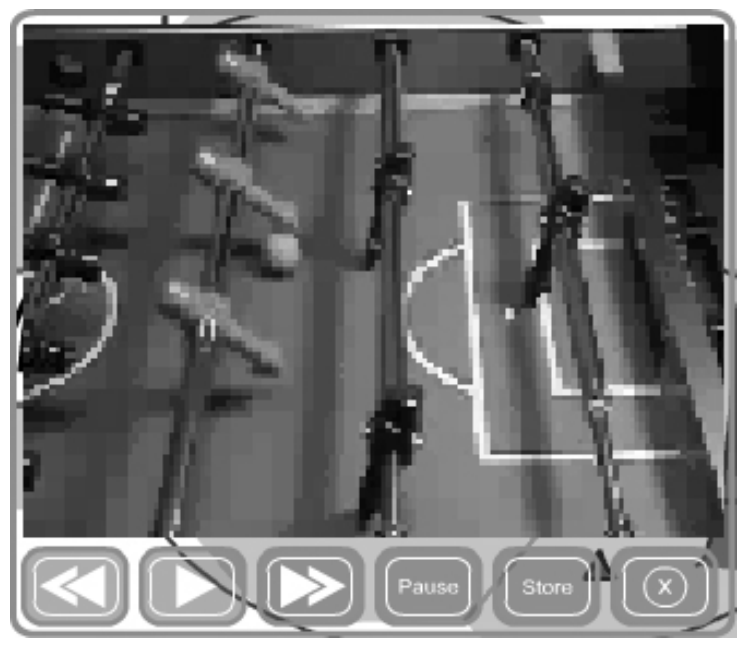

\subsection{Better Bets $(B B)$}

The BB service provided an HTML-based electronic betting service, where users were given various options to bet on different outcomes of a football match. Again this service was a static service where the service's content was supported by the terminal (i.e. HTML player). The difference with the BB service was that the content was not downloaded as set via FTP but rather accessed via the internet as a traditional web page. Since the HTML player supports offline and online web pages no additional player/decoder is required. The service icon, description and subscription acknowledgement fly-out is shown in Figure 8. 
Figure 8 BB service icon, description, acknowledgement

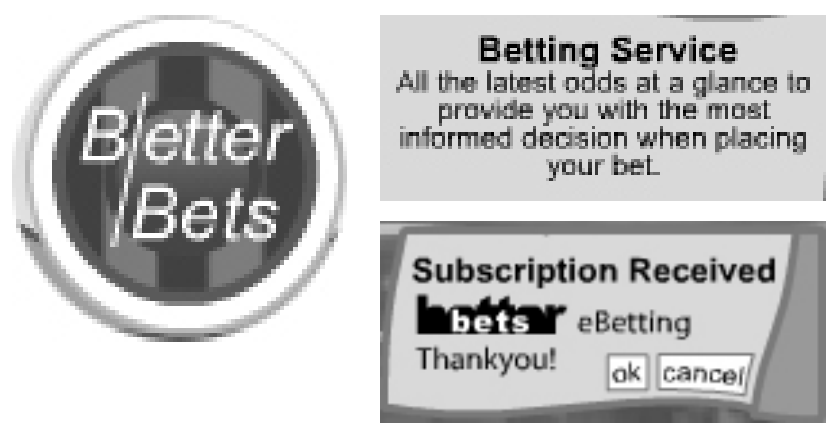

Figure 9 BB internet pages
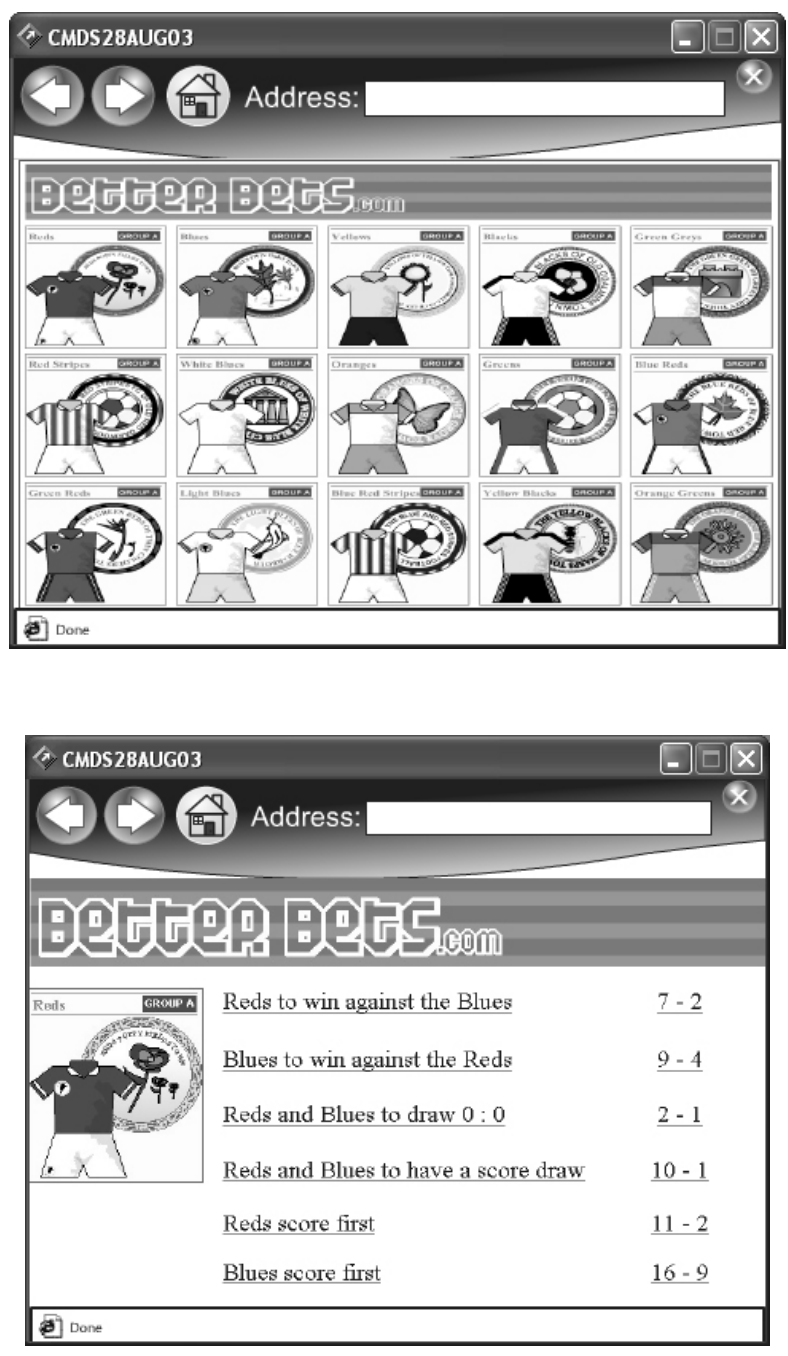


\subsection{Lost DVB Reception (LR)}

The MA service was available to the user via both delivery channels with alternate qualities. Thus if during the consumption of the MA service, the terminal network manager detected the loss of DVB-T reception, this was notified to the ESG which automatically offered the user the option to consume the GPRS version of the service, through the service subscription box shown in Figure 10.

Figure 10 Service subscription box for lost reception service

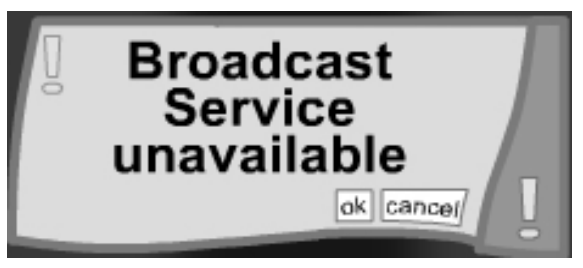

\subsection{End user terminal}

The end-user terminal was used for displaying TV programmes and additional services, and was based on a web pad. Its main physical parameters consisted of an 8.4" (square) TFT display with a 4-wire resistive touch screen, built-in stereo speakers and mono microphone with external jacks for headphone/microphone and a weight of less than $0.9 \mathrm{~kg}(2 \mathrm{lbs})$ with case dimensions approximately $250 \times 210 \times 35 \mathrm{~mm}(9.9 \times 8.3 \times$ 1.4 in). It also had six user-programmable buttons, three programmable indicator LED's, and a clickable navigation wheel. The end-user terminal is shown in Figure 11.

Figure 11 End-user terminal

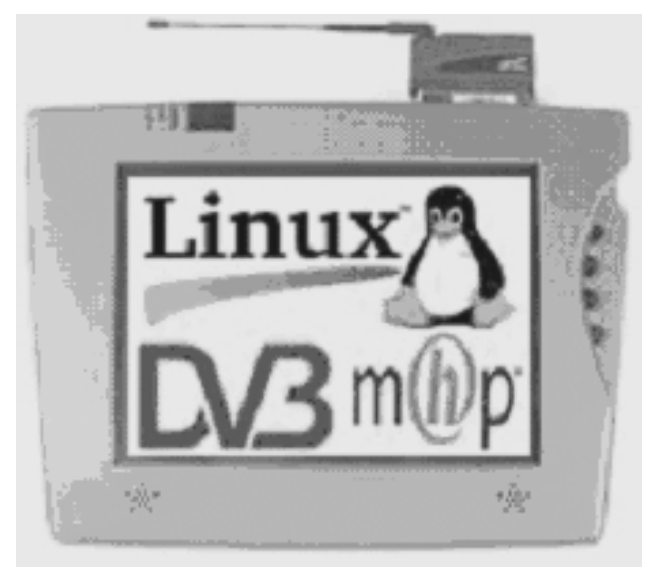

The main tasks of the terminal was to access TV programmes and a Personal Video Recorder using a Control Stick, discover and subscribe to services, present these services for selection by the end user using an Electronic Service Guide, and then present the service user interface for service consumption by the end user. 


\subsubsection{Control stick}

As default, the user interface provided a default user interface layer. This default layer provided default television controls as opposed to service specific layers and controls. The default layer provided a set of static control widgets that allowed users/viewers to control the common system functionalities irrespective of the current running service. These functions included:

- channel changing

- volume control

- user preferences

- Personal Video Recorder (PVR) controls

- Electronic Service Guide (ESG) access

- default control minimize.

These controls were presented to the user as an onscreen graphical representation of a remote control and are shown in Figure 12. These controls were the root of the user interface control hierarchy.

Figure 12 TV control stick



\subsubsection{Electronic Service Guide (ESG)}

The Electronic Service Guide (ESG) was a terminal-resident application that provided a graphical representation and user access mechanism to all services available to the terminal: DVB services from the DVB-SI and IP services. It also provided a textual service description and subscription method for these services. The Terminal and a User Manager maintained a database of terminal characteristics and user preferences, and used this to filter the complete list of services to present to the user only those services they are interested in and that their terminal could consume.

The ESG's service discovery mechanism determined the DVB services by scanning the DVB Service Information (DVB-SI) multiplexed within the transport stream, IP services by listening to the terminal network manager to receive IP service 
announcements that consisted of unicast, multicast services, and services that combined DVB and IP components. It used this service information to aggregate all available services and all selected services for presentation to the user in the form of a list of service icons that could be scrolled through up/down scroll buttons, as shown in Figure 13.

Figure 13 Electronic service guide

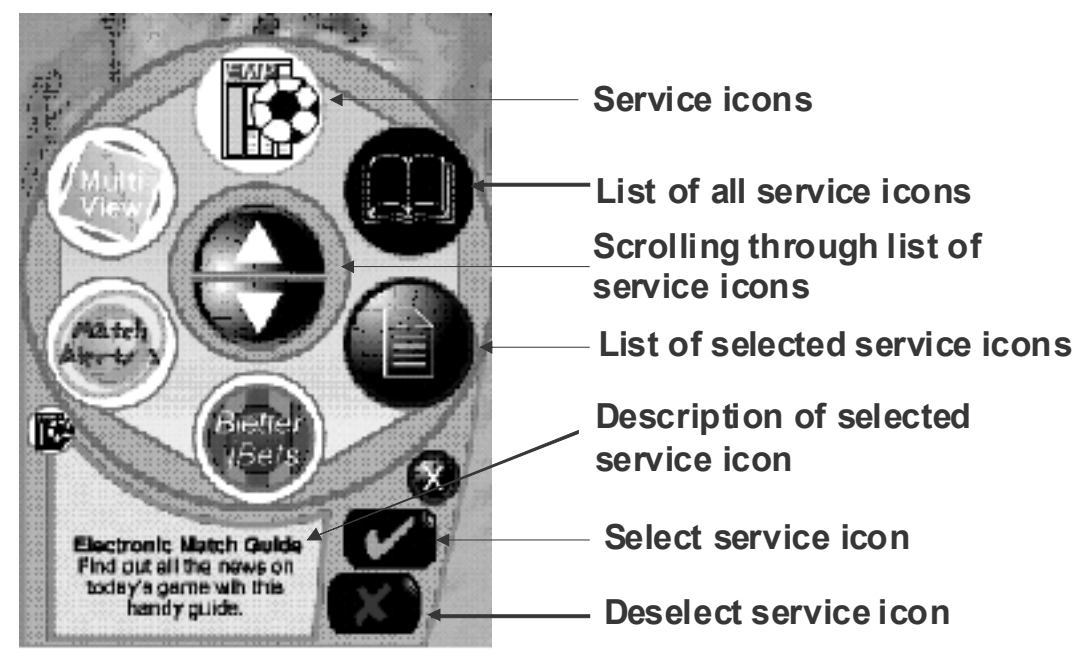

To consume a service the user first subscribed to it via the ESG by selecting the icon and then the Select Service Icon tick. The ESG then informed the terminal network manager what service the user had subscribed to. A service could only be consumed once all its relevant service components had been downloaded on to the terminal. The ESG downloaded the service package via the storage manager's BTFTP client or Object carousel client depending on the service component type stores. These components could have consisted of video files, audio files, java classes, GUI information, and associated metadata of each separate service session. Then the ESG initiated the display of the service user interface and determined from the terminal network manager if services were to be consumed over a DVB-T link or via an IP channel.

If a service was available to the user via both delivery channels, the user could specify one or the other. This preference was maintained by the ESG and was applied to service consumption. The ESG was also integrated with the Personal Video Recorder (PVR) stack which allowed traditional television 'channel hopping' as well as enhanced functionality that the PVR provided such as time-shifted viewing that was needed to store the main AV programme when the user was viewing service components.

Although the ESG 'client side code' was complex, the ESG was still a service, one that was either terminal resident or could be replaced by downloading an alternative ESG/EPG service. 


\section{Fast prototype simulation and user trial of service concepts}

A computer graphics animation tool was used to simulate the operation of the system as perceived at the end-user terminal. The graphics tool combined audiovisual movie objects with graphical objects. Interactive elements were added to the simulator by adding software scripts onto the graphical objects so that mouse clicks over a graphical object initiated a programmed sequence of actions. Furthermore software scripts were associated with the entire audiovisual movie objects or with individual frames of one or more audiovisual movie frames. This allowed each of the individual service components and user interface graphical components to be simulated and interconnected with each other.

User trials of the simulated converged broadcast and cellular football sport services were conducted on users to determine user acceptability. A storyboard provided an overview of how to navigate the user interface. Users then navigated through the services without the document and completed a questionnaire.

\subsection{Questionnaire and results}

The questionnaire consisted of 40 questions and allowed users to assess the look and feel of the proposed prototype system, the design of the various TV and Electronic Service Guide interfaces, the usefulness of the proposed services and the appropriateness of the physical design of the terminal. Thirty-three users from a young upwardly mobile, computer literate cross section of society were tested. These users were selected because they were Brunel University Internet Engineering undergraduates with a strong interest in the mobile internet and the services they were testing were considered an improvement on what is currently available on the mobile internet. A set of PowerPoint slides provided each user with a visual storyboard of how to navigate the interface of the prototype converged system. They used the storyboard to navigate through the services in the prescribed order. This took about 30 minutes. They then navigated through the services without the storyboard. Finally they completed the questionnaire. The questionnaire and results are shown in Table 1. The table is organised as a list of numbered questions in the first two columns. For each question the grade can be assigned a value 1 to 5 against the description and this is given in the third column. The fourth and fifth column provides the mean and standard deviation result for each question. Figure 14 provides a graphical presentation of the results of each question. On the vertical axis is listed the question number whilst on the horizontal axis is the percentage of users who selected Grade 1 $\left(1^{\text {st }}\right.$ bar $), 2\left(2^{\text {nd }}\right.$ bar $), 3$ ( $3^{\text {rd }}$ bar $), 4$ ( $4^{\text {th }}$ bar $)$, and 5 ( $5^{\text {th }}$ bar $)$. 
Table 1 User trial questionnaire and results

\begin{tabular}{|c|c|c|c|c|}
\hline $\begin{array}{l}\text { Question } \\
\text { number }\end{array}$ & Question & $\begin{array}{l}\text { Grade } \\
(1 \ldots . .5)\end{array}$ & Mean & $\begin{array}{l}\text { Std. } \\
\text { dev. }\end{array}$ \\
\hline 1 & $\begin{array}{l}\text { How intrusive was the TV control interface on } \\
\text { the background video? }\end{array}$ & $\begin{array}{l}\text { Noticeable... } \\
\text { Unnoticeable }\end{array}$ & 2.6 & 1.1 \\
\hline 2 & $\begin{array}{l}\text { How coherent was the layout of TV control user } \\
\text { Interface? }\end{array}$ & $\begin{array}{l}\text { Poor... } \\
\text { Excellent }\end{array}$ & 3.4 & 1.3 \\
\hline 3 & How intuitive was the use of the TV controls? & $\begin{array}{l}\text { Poor... } \\
\text { Excellent }\end{array}$ & 3.5 & 1.0 \\
\hline 4 & $\begin{array}{l}\text { How sufficiently colourful were the TV } \\
\text { controls? }\end{array}$ & $\begin{array}{l}\text { Insufficient... } \\
\text { Sufficient }\end{array}$ & 3.8 & 1.3 \\
\hline 5 & $\begin{array}{l}\text { How useful was the use of the personal video } \\
\text { recorder? }\end{array}$ & $\begin{array}{l}\text { Poor... } \\
\text { Excellent }\end{array}$ & 3.2 & 1.2 \\
\hline 6 & $\begin{array}{l}\text { How intrusive was the ESG interface on the } \\
\text { background video? }\end{array}$ & $\begin{array}{l}\text { Noticeable... } \\
\text { Unnoticeable }\end{array}$ & 2.0 & 1.4 \\
\hline 7 & $\begin{array}{l}\text { How consistent was the layout of ESG control } \\
\text { user interface? }\end{array}$ & $\begin{array}{l}\text { Poor... } \\
\text { Excellent }\end{array}$ & 3.7 & 1.1 \\
\hline 8 & $\begin{array}{l}\text { How sufficiently colourful were the ESG } \\
\text { controls and icons? }\end{array}$ & $\begin{array}{l}\text { Insufficient... } \\
\text { Sufficient }\end{array}$ & 4.1 & 1.0 \\
\hline 9 & How intuitive was the use of the ESG controls? & $\begin{array}{l}\text { Poor... } \\
\text { Excellent }\end{array}$ & 3.5 & 1.2 \\
\hline 10 & $\begin{array}{l}\text { How representative of services are the service } \\
\text { icons? }\end{array}$ & $\begin{array}{l}\text { Poor... } \\
\text { Excellent }\end{array}$ & 3.5 & 1.1 \\
\hline 11 & $\begin{array}{l}\text { How informative of services are the service } \\
\text { descriptions? }\end{array}$ & $\begin{array}{l}\text { Insufficient... } \\
\text { Sufficient }\end{array}$ & 3.5 & 1.1 \\
\hline 12 & $\begin{array}{l}\text { How acceptable is the service subscription } \\
\text { process? }\end{array}$ & $\begin{array}{l}\text { Poor... } \\
\text { Excellent }\end{array}$ & 3.5 & 1.2 \\
\hline 13 & $\begin{array}{l}\text { Would you find the electronics service guide } \\
\text { easy to discover new services? }\end{array}$ & $\begin{array}{l}\text { Easy... } \\
\text { Difficult }\end{array}$ & 2.7 & 1.3 \\
\hline 14 & How useful would you find the EMP service? & $\begin{array}{l}\text { Not } \\
\text { interested... } \\
\text { Very } \\
\text { interested }\end{array}$ & 3.9 & 1.0 \\
\hline 15 & How useful would you find the MVF service? & $\begin{array}{l}\text { Useless... } \\
\text { Useful }\end{array}$ & 4.2 & 1.0 \\
\hline 16 & $\begin{array}{l}\text { How useful would you find the high quality } \\
\text { match alerts service? }\end{array}$ & $\begin{array}{l}\text { Useless... } \\
\text { Useful }\end{array}$ & 4.0 & 0.8 \\
\hline 17 & $\begin{array}{l}\text { How useful would you find the alternate quality } \\
\text { match alerts service? }\end{array}$ & $\begin{array}{l}\text { Useless... } \\
\text { Useful }\end{array}$ & 3.8 & 1.0 \\
\hline 18 & How useful would you find the BB service? & $\begin{array}{l}\text { Useless... } \\
\text { Useful }\end{array}$ & 3.6 & 1.2 \\
\hline 19 & $\begin{array}{l}\text { How useful would you find the out of area DVB } \\
\text { service for match alerts? }\end{array}$ & $\begin{array}{l}\text { Useless... } \\
\text { Useful }\end{array}$ & 3.7 & 0.9 \\
\hline 20 & $\begin{array}{l}\text { How acceptable was the intrusion was the EMP } \\
\text { service on the main video? }\end{array}$ & $\begin{array}{l}\text { Unacceptable... } \\
\text { Acceptable }\end{array}$ & 3.2 & 1.3 \\
\hline
\end{tabular}


Table 1 User trial questionnaire and results (continued)

\begin{tabular}{|c|c|c|c|c|}
\hline $\begin{array}{l}\text { Question } \\
\text { number }\end{array}$ & Question & $\begin{array}{l}\text { Grade } \\
(1 \ldots 5)\end{array}$ & Mean & $\begin{array}{l}\text { Std. } \\
\text { dev }\end{array}$ \\
\hline 21 & $\begin{array}{l}\text { How acceptable was the automatic returning for } \\
\text { the TV set to the football channel on selection } \\
\text { of MVF service? }\end{array}$ & $\begin{array}{l}\text { Unacceptable... } \\
\text { Acceptable }\end{array}$ & 3.6 & 1.2 \\
\hline 22 & $\begin{array}{l}\text { How acceptable was the intrusion was the high } \\
\text { quality MA service on the main video? }\end{array}$ & $\begin{array}{l}\text { Unacceptable... } \\
\text { Acceptable }\end{array}$ & 3.7 & 1.1 \\
\hline 23 & $\begin{array}{l}\text { How acceptable was the intrusion was the } \\
\text { alternate quality MA service on the main } \\
\text { video? }\end{array}$ & $\begin{array}{l}\text { Unacceptable... } \\
\text { Acceptable }\end{array}$ & 3.2 & 1.1 \\
\hline 24 & $\begin{array}{l}\text { How acceptable was the intrusion was the BB } \\
\text { service on the main video? }\end{array}$ & $\begin{array}{l}\text { Unacceptable... } \\
\text { Acceptable }\end{array}$ & 3.0 & 1.2 \\
\hline 25 & $\begin{array}{l}\text { How much are you prepared to pay for EMP } \\
\text { service? }\end{array}$ & Low... High & 2.3 & 1.2 \\
\hline 26 & $\begin{array}{l}\text { How much are you prepared to pay for MVF } \\
\text { service? }\end{array}$ & Low... High & 2.6 & 1.4 \\
\hline 27 & $\begin{array}{l}\text { How much are you prepared to pay for the high } \\
\text { quality MA service service? }\end{array}$ & Low... High & 2.3 & 1.2 \\
\hline 28 & $\begin{array}{l}\text { How much are you prepared to pay for the } \\
\text { alternate quality MA service? }\end{array}$ & Low... High & 1.9 & 1.2 \\
\hline 29 & $\begin{array}{l}\text { How much are you prepared to pay for the BB } \\
\text { service? }\end{array}$ & Low... High & 1.8 & 1.3 \\
\hline 30 & $\begin{array}{l}\text { How much did you prepared to pay for the out of } \\
\text { DVB area service for match alerts? }\end{array}$ & Low... High & 2.0 & 1.1 \\
\hline 31 & $\begin{array}{l}\text { How appropriate is a screen size of } 8.4 " \text { (square) } \\
\text { for a converged TV and cellular phone? }\end{array}$ & Low... High & 3.4 & 1.2 \\
\hline 32 & $\begin{array}{l}\text { How appropriate is a touch screen interaction for } \\
\text { a converged TV and cellular phone? }\end{array}$ & Low... High & 4.3 & 0.9 \\
\hline 33 & $\begin{array}{l}\text { How appropriate is a screen size of } 0.9 \mathrm{~kg} \text { for a } \\
\text { converged TV and cellular phone? }\end{array}$ & Low... High & 2.4 & 1.2 \\
\hline 34 & $\begin{array}{l}\text { Was it easy to navigate through the system using } \\
\text { the guide? }\end{array}$ & $\begin{array}{l}\text { Easy } \ldots \\
\text { Difficult }\end{array}$ & 2.0 & 1.2 \\
\hline 35 & $\begin{array}{l}\text { Was it easy to navigate through the second time } \\
\text { without the guide? }\end{array}$ & $\begin{array}{l}\text { Easy } \ldots \\
\text { Difficult }\end{array}$ & 2.1 & 1.0 \\
\hline 36 & $\begin{array}{l}\text { Do you find the overall layouts of the user } \\
\text { interfaces logical and consistent? }\end{array}$ & $\begin{array}{l}\text { Poor... } \\
\text { Excellent }\end{array}$ & 3.1 & 1.1 \\
\hline 37 & $\begin{array}{l}\text { How intuitive did you find navigating about the } \\
\text { system? }\end{array}$ & $\begin{array}{l}\text { Unintuitive... } \\
\text { Intuitive }\end{array}$ & 3.1 & 1.1 \\
\hline 38 & $\begin{array}{l}\text { Can tasks be performed in a straight-forward } \\
\text { manner? }\end{array}$ & $\begin{array}{l}\text { Poor... } \\
\text { Excellent }\end{array}$ & 3.7 & 1.0 \\
\hline 39 & $\begin{array}{l}\text { How coordinated was the color designs of the } \\
\text { user interfaces? }\end{array}$ & $\begin{array}{l}\text { Poor... } \\
\text { Excellent }\end{array}$ & 3.7 & 1.3 \\
\hline 40 & $\begin{array}{l}\text { How appropriate were the shape designs of the } \\
\text { user interfaces? }\end{array}$ & $\begin{array}{l}\text { Poor... } \\
\text { Excellent }\end{array}$ & 3.4 & 1.3 \\
\hline
\end{tabular}


Figure 14 Graph of user trial questions against results

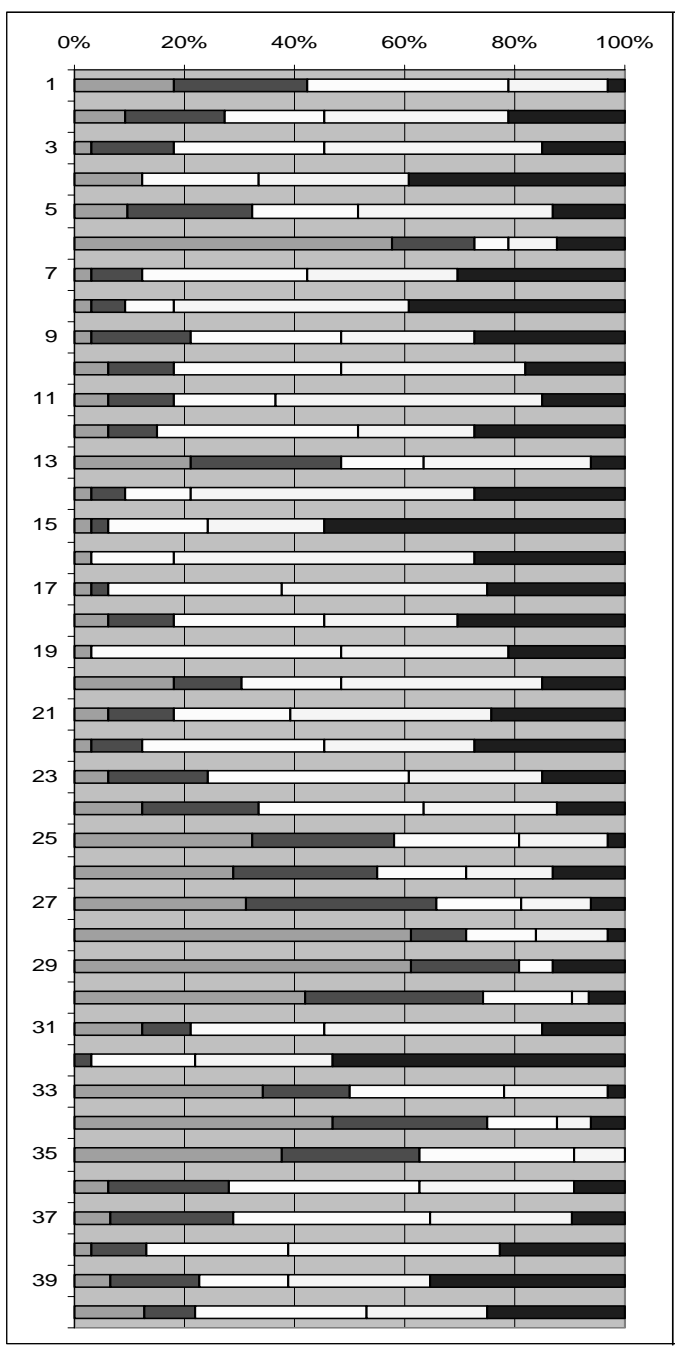

\subsection{Analysis of results}

\subsubsection{Analysis of user trial response to questionnaire} Intrusiveness (Table 1: question 1, 6, 20, 22, 23, 24)

For the TV control the overall opinion was that the intrusiveness was acceptable. Overall the TV controls did not take up too much screen space at the edge of the screen but was noticeable when watching TV which was distractive if it had not been minimised $\left(\mu_{1}=2.6\right)$. This was satisfactory if access to some options was required but for browsing and watching at the same time the TV interfaces was intrusive.

For the ESG interface, the overall opinion was that it was extremely noticeable $\left(\mu_{6}=2.0\right)$. It took up the majority of the screen and made it very hard to see what is going on, on the screen at the same time, as shown in Figure 15. 


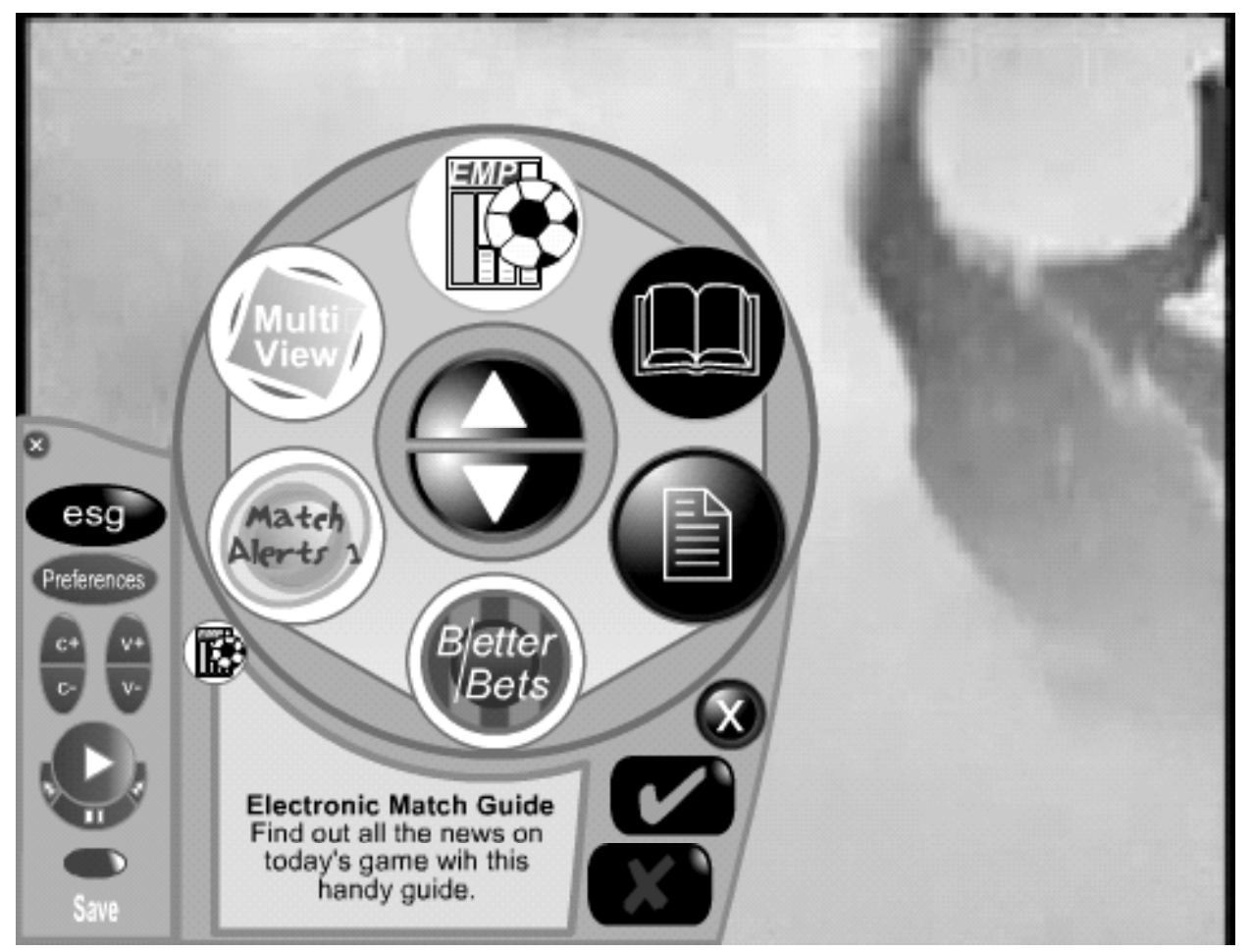

For the EMP service the general opinion was that it was acceptably intrusive $\left(\mu_{20}=3.2\right)$. This was surprising since it took up the whole screen and did not allow TV to be watched whilst consuming the service at the same time, as shown in Figure 2. Nevertheless the web page did make good use of the screen and was easy to read and simple to navigate. This opinion extended to the football MA service both high quality $\left(\mu_{22}=3.7\right)$, as shown in Figure 7 , and alternate quality version $\left(\mu_{23}=3.2\right)$, as shown in Figure 6 and to the BB service $\left(\mu_{24}=3.0\right)$, as shown in Figure 8 .

The overall opinion therefore was that intrusiveness was acceptable if the whole screen was used but not if a significant part of the screen was used with the TV being played in the background.

\section{TV controls (Table 1: question 2, 3, 4)}

The overall opinion was that the layout of the TV controls was good ( $\mu_{2}=3.4$ ) mainly because they were modelled in the same way as a normal TV remote control with a play, pause, rewind, and fast forward buttons, making its operation easily identifiable. There was an overall good response to the intuitiveness of the TV controls $\left(\mu_{3}=3.5\right)$ because the design was simple. The overall opinion on the colour of the TV controls was good $\left(\mu_{4}=3.8\right)$ mainly because the colour of the controls stood out well and made the controls easier to recognise and use through bright, easy-to-identify colours. 


\section{ESG (Table 1: question 7, 8, 9)}

The ESG was the main interface through which services were subscribed and accessed, as shown in Figure 13. Opinion on the layout of the ESG interface was mixed. The layout of the ESG was organised in an orderly manner $\left(\mu_{7}=3.7\right)$ with the service icons ordered in a nice formation $\left(\mu_{9}=3.5\right)$ with attractive colour schemes $\left(\mu_{8}=4.1\right)$. However the layout did take up a lot of space and the duplicate ' $x$ ' icons at the bottom of the ESG led to some confusion regarding which closed the ESG and which cancelled the command.

On the whole the opinion on colour scheme of the ESG controls was favourable because it blended well with the colour scheme of the TV controls. However whilst some users liked the colour scheme others totally disliked it.

\section{Services (Table 1: question 10, 11, 12)}

Opinion on the effectiveness of the service icons was mixed because although they were bold and easy to recognise it was not always clear what each icon stood for $\left(\mu_{10}=3.5\right)$. For example an icon with 'EMP' did not provide any indication what service it represented. Similarly 'Multi View' service icon left users wandering Multi View what? Conversely, 'Match Alerts' and 'Better Bets' seemed to explain what service they represented quite well. The service captions explained the services in one sentence. It was generally felt that the service captions at the bottom of the ESG were of great help in explaining what the service was all about $\left(\mu_{11}=3.5\right)$ and made up for the vagueness of the service icons. Although the subscription process for services was quick and easy to use it did leave some users vaguely unsure of what they were supposed to do and what was happening in the subscription process $\left(\mu_{12}=3.5\right)$. For example, it was felt that four selections to consume a service were too much and needed more explanation why they were required:

1 select service icon on ESG

2 subscribe to service by selecting ' $V$ '

3 acknowledge subscription of service

4 consume service through the second selection of the service icon outside the ESG.

Usefulness of services (Table 1: question 14, 15, 16, 17, 18, 19)

Opinion on the usefulness of the services was mixed. It was felt that the EMP service $\left(\mu_{14}=3.9\right)$ was useful since it provided a good source of information about which matches were being played. The MVF service was also thought to be useful $\left(\mu_{15}=4.2\right)$ because it provided the user the choice of watching the game from different angles. The high quality MA service $\left(\mu_{16}=3.8\right)$ and alternate quality $\left(\mu_{17}=3.6\right)$ service were also thought to be useful because these allowed users to be informed of what was going on at other matches whilst they were watching another match. There was a mixed response to alternative quality MA. On the one hand, the user obtained a nicely presented report on the latest score whilst, on the other hand, it was definitely a disappointing alternative to a video clip of the latest score. The BB service also had mixed response $\left(\mu_{17}=3.6\right)$. Some viewers had strong personal opinions on the usefulness of a betting service at all whilst other users complained at having to leave the TV whilst making bets. The alternate 
service provisioning of the MA service whilst out of area was thought to be handy but again was a disappointing alternative to the video clip version of the service.

Payment (Table 1: question 25, 26, 27, 28, 29, 30)

The general opinion was that most users were not prepared to pay for any of the services because users were used to receiving perceived 'free' football services from TV and objected to any additional payment. This was the case for EMP $\left(\mu_{25}=2.3\right)$, MVF $\left(\mu_{27}=2.6\right)$, MA high quality $\left(\mu_{27}=2.3\right)$, MA alternate quality $\left(\mu_{28}=1.9\right), \mathrm{BB}\left(\mu_{29}=1.8\right)$. Users particularly objected to paying for the BB service because this payment was in addition to placing any bets.

\section{Appropriateness of the physical size (Table 1: question 31, 32)}

The general reaction to the 8.4" tablet PC screen was that is was a good size $\left(\mu_{31}=3.4\right)$ because it was relatively easy to travel with if being used 'on the go' and yet big enough to watch TV and make use of the different services. Other users felt that the physical device was simply too big and would weigh far too much to be portable enough $\left(\mu_{33}=2.4\right)$. Another major concern was its cost. Some users argued that the use of a notebook PC with DVB-T and UMTS radio interface enabled through PCMCIA card interface would be more preferable because it could provide additional features such as word processing. This would therefore not rule out the use of a keypad.

The overall conclusion was that a device cannot be deemed to be perfectly portable without it being able to be fit into a pocket.

Navigation (Table 1: question 34, 35)

Users found it difficult to navigate through the system because it was a linear simulation of the system operation $\left(\mu_{34}=2.0\right)$ even on the second time of use $\left(\mu_{35}=2.1\right)$. The linear simulation meant that there was a very limited choice to choose from since selecting a wrong button often resulted in no response from the system. This is a limitation of the simulation technique which has now been improved to be nonlinear.

\section{Consistency (Table 1: question 36)}

The ESG interface was centralised and it was easy to recognise the function of each key. The functionality of the TV control buttons were also easy to work out $\left(\mu_{36}=3.1\right)$.

\section{Straightforwardness (Table 1: question 38)}

Although the system was hard to use, the tasks were relatively easy to carry out once understood $\left(\mu_{38}=3.7\right)$.

\section{Design of interface (Table 1: question 39, 40)}

The design of the remote control was a good idea because its design was recognisable and did not take up much space but the ESG was quite large and its design and shape took a up a too large quantity of the screen $\left(\mu_{40}=3.4\right)$. The sharp eye-attracting colour of 
the remote and ESG was not always received well, with some users preferring a colour that was less bright $\left(\mu_{39}=3.7\right)$.

\subsubsection{Alternate designs}

Users were asked to propose alternate design ideas for the user interface. The main issue was the obtrusiveness of the ESG. The suggestions proposed to reduce the size, shape colour and design of the ESG:

- Introduce transparency in the green areas of the screen.

- Restrict the ESG shape to the top or bottom edge of the screen. The icons could be organised horizontally at the top or bottom of the screen in a linear fashion.

- Save screen space by presenting either the TV controls or the ESG on the screen but not both at the same time.

- Allow users to choose the colour of the user interface.

- Allow user to choose from different types of user interfaces.

- The ESG close button should be placed in a position familiar to most applications: top right-hand corner of the ESG.

Since some users totally objected to the betting service, there should have been an option to filter out those services which are totally objectionable to users.

Some users felt that the device could benefit from having some removable storage. Video clips could then be saved onto memory cards and shared with other users using either UMTS or some physical exchange.

It was felt that if the user did not like the UI then he or she should have the option of downloading a different skin for the user interface based on his or her own preference. This would then provide the user with the option of selecting various options:

- Modification of the PVR buttons to be less close together.

- Use different type of controls for the volume control (wheel).

- Provide a mute button.

- Provide different size, shape colour and design.

It was felt that less space for control signals could have been combined with spoken commands rather than only using a touch screen. This would also provide an easier way of controlling the device.

It was felt that the TV context must be maintained by designing the TV control and ESG so that it impinges as little as possible on the TV context. This could have been achieved by always keeping the TV context party visible or visible through a partly transparent TV control and ESG overlays.

It was felt that 3D graphics could have been used to reduce the amount of screen space used in the ESG. It was felt that the sound should always remain on since the user could then at least hear what is going on even if he or she could not always see what was going on. 


\subsubsection{Proposal for new services}

Users were asked to propose alternate services ideas. A recurrent theme among all the viewers was that they all had opinions on what services they thought would be useful to them and what services they were not interested in. Therefore a system that would allow viewers to select their preferred services would ensure that users were only presented with services that were of interest to them.

A number of viewers felt that the killer application of digital TV is TV with the majority of viewers only interested in ways to enhance TV viewing. Their opinion was that watching TV and using a computer were fundamentally different tasks and that whilst there would be a small niche market for hybrid use, the majority or viewers would not be attracted to a computer-TV merger. Conversely a number of users expressed great interest in receiving services that supplemented the main TV viewing especially if it was combined with a personal interest such as a sport. This diversity of views indicated that a system is required to configure settings of a portable interactive TV to filter out those services that are not of interest to the viewer.

\section{Additional football services}

Users were specifically asked to propose alternate football service ideas which are listed in Table 2.

Table 2 Alternate football service ideas

\begin{tabular}{ll}
\hline Idea & \multicolumn{1}{c}{ Description } \\
\hline $\begin{array}{l}\text { General information } \\
\text { page }\end{array}$ & $\begin{array}{l}\text { A free page was proposed that provides information about the service } \\
\text { and provides users with help for any problems with the system they } \\
\text { might experience. }\end{array}$ \\
Full news service & A service was proposed that provides full coverage for all league \\
& teams. Like the EMP which provided match information about two \\
& teams this service would provide a basic run down of all football news \\
including signings, injuries previous results, cup ties etc. The reason \\
why this service would be useful is because it would provide more \\
wide ranging information. \\
A service was proposed that would provide league's listing for all \\
football divisions. Unlike the EMP service and the Full News Service, \\
this service would just provide the league tables for each football \\
division. This would be useful because one common desired piece of \\
information in the football world is the current leagues tables.
\end{tabular}

\section{Additional alternate services}

Many users did not like the fact that the example service was geared towards football and thus suggested a range of alternatives that are listed in Table 3. 
Table 3 Alternate service ideas

\begin{tabular}{|c|c|}
\hline Idea & Description \\
\hline Movie cinema service & $\begin{array}{l}\text { This service was proposed to include information and trailers on the } \\
\text { latest movies. This was considered a good service since movies } \\
\text { have a much wider appeal toward people. }\end{array}$ \\
\hline Video on demand & $\begin{array}{l}\text { A service was proposed where the viewer can see any movie at any } \\
\text { time and maybe saves movies locally to see at specific times later. }\end{array}$ \\
\hline Music service & $\begin{array}{l}\text { This service was proposed to include information about the music } \\
\text { charts and music samples for all the latest albums and singles. This } \\
\text { was considered a good service since it would be more popular and } \\
\text { attract larger audiences that are more frequently accessed because } \\
\text { music has a more all round larger appeal. }\end{array}$ \\
\hline $\begin{array}{l}\text { Global positioning system } \\
\text { service }\end{array}$ & $\begin{array}{l}\text { A service was proposed that would identify location and be } \\
\text { integrated with various online maps and information databases to } \\
\text { relay geographical and local information to the use such as } \\
\text { where the nearest location of a public house (pub) and/or police } \\
\text { station } \text { etc. }\end{array}$ \\
\hline Stocks and shares service & $\begin{array}{l}\text { This service was proposed to be available to the user where (s)he } \\
\text { can instantly check the latest financial bulletins whilst still } \\
\text { listening/watching a business news channel. }\end{array}$ \\
\hline Local news and weather & $\begin{array}{l}\text { Since localisation information is available, this service was } \\
\text { proposed to relay local news weather and other local information } \\
\text { such as nearest train/bus station, next train/bus. }\end{array}$ \\
\hline Gaming & $\begin{array}{l}\text { This was a service that was proposed that could possibly generate } \\
\text { money when using a "pay to play" system and could appeal to many } \\
\text { users. It could run alongside a games DVB channel that could } \\
\text { encourage and schedule big multiplayer gaming events. However } \\
\text { this feature may require an upgrade in processing power, server } \\
\text { processing and graphics acceleration. }\end{array}$ \\
\hline Shopping/auction & $\begin{array}{l}\text { A service was proposed that allowed users to buy from online shop. } \\
\text { This includes holidays and services as well as consumable items } \\
\text { such as clothes etc. }\end{array}$ \\
\hline Phone communications & $\begin{array}{l}\text { This proposed service would allow users to use the system as a } \\
\text { phone for conversation. File sharing facilities could also enable the } \\
\text { sharing of multimedia that had been accessed through the services. }\end{array}$ \\
\hline
\end{tabular}

\subsubsection{Proposal for new questions in the questionnaire}

Finally users were asked to propose alternate ideas for the questionnaire that would possibly reveal their opinion on terminals for a converged broadcast and cellular networks. 
Table 4 New questions for questionnaire

\begin{tabular}{ll}
\hline Question & \multicolumn{1}{c}{ Description } \\
\hline $\begin{array}{l}\text { Are you interested in watching TV } \\
\text { programmes and services on the move? }\end{array}$ & $\begin{array}{l}\text { A lot of people prefer to watch TV at home rather than } \\
\text { outside. This question is designed to determine whether } \\
\text { people are comfortable with the concept of watching TV } \\
\text { whilst on the move. }\end{array}$
\end{tabular}

How much would you be prepared to pay for this terminal?

This question should have been asked since the users had no idea how much they would have to pay for this product.

What colour scheme would you prefer? Since there were few people who did not like the colour scheme of the proposed terminal, this question could have been asked to gather information on which colour scheme they would have preferred.

Are you satisfied with the quality of the video?

Do you find the design of the web pages (BB and EMP) satisfactory?

Would menu transparency interest you?

Would being able to minimise services interest you?

How long do you think you will use the device continuously at any one time?

Did you find the screen size of 8.4" too large or too small for a portable device?

Would you rather pay as you consume each service or prepay on a single subscription charge or pay as part of the connection charge to pay at a later date?
This question was designed to determine whether people are happy with the overall quality of the video clips or whether the quality would need to be improved. This question should also be linked with a question on whether people are prepared to pay more for additional quality.

This question would determine whether people were satisfied with the static websites that they access, if they like the design or find it poor.

One complaint that reoccurred was that the ESG was intrusive and stopped the user from watching TV. This question would determine whether a user was interested in using transparency on the menu to continue watching TV whilst using the ESG

This question is based on the fact that most users disliked the intrusion effect of services stopping the user watching the main TV. A minimise button would shrink the service to the bottom of the page and allow you to watch the service when you were more prepared. Alternatively a squirrel function would allow the service to be squirreled away so that the user can view it at a more convenient time.

This question is concerned with the duration of use so that battery life can be dimensioned to support the required amount of usage from the device.

This question is designed to determine if users would be happier with a smaller device for watching TV and consuming multimedia services.

Include in the payment questions the option of not paying anything for the services. This was not included in the original questionnaire. 


\section{Conclusion}

Overall, a lot of users were interested in a terminal that was connected to a converged broadcast and cellular network and were keen to find out more about the types of services that such a system could provide. This was evident from the imaginative suggestions for new services that were proposed. However, many of the users were not prepared to pay much at all for the services. Their opinion was that if TV and internet are 'free' or at least restricted to a fixed subscription price (for TV) or a fixed subscription price and connection charge (for internet) then why pay for these additional services? Therefore, the main conclusion is that if viewers are given the option of paying now (pay-per-view) or before (as in the case for subscription) or after (as in the case of phone bills), this set of viewers would rather pay before or after. This would avoid the painful sight of watching money incrementally being spent. Thus a flexible system is required that would allow viewers to choose their method of payment.

There was much objection to using too much of the TV screen space for the TV controls and the ESG and there were a number of useful suggestions to reduce the size and transparency of the TV controls and ESG in favour of the main TV context. There were also some concerns with the existing ESG interface because its functionality was a little vague and not straightforward enough.

There was also a degree of concern regarding the optimal size and weight of the proposed terminal device with some viewers finding an 8.4" tablet PC an acceptable size whilst others preferring pocket-size devices. A number of viewers argued that a palm top PC would be more preferable than a tablet PC.

A number of viewers objected to additional services impinging on the main TV service whilst others expressed an interest in receiving services that supplemented the main TV viewing especially if it is combined with a personal interest such as a sport. The user manager within the terminal could have used its database of user preferences to filter out those services that the user is not interested. However since only one type of sports service was created and user preference filter was not implemented in the terminal simulator, it could not be used to filter out services.

The degree of interest aroused by this concept is reflected in the many viewers who specifically expressed a wish to participate in the trial of the final implemented device. The prime issues are therefore clear: the economical use of screen space, cost of services, size and weight of device, simplicity of navigation, range of services available, and varying degrees of user interactivity.

\section{Acknowledgment}

The authors gratefully acknowledge the support for this work that is funded by the EU under the IST programme as the project CISMUNDUS (Convergence of IP-based Services for Mobile Users and Networks in DVB-T and UMTS Systems): http://www.brunel.ac.uk/project/cismundus 


\section{References}

1 Sigurdson, J. and Ericsson, P. (2003) 'New services in 3G - new business models for streaming and video', International Journal of Mobile Communications, Vol. 1, Nos. 1-2, pp.15-34.

2 Kraal, C.J. (1996) 'Developing for interactive services in digital TV', International Broadcasting Convention (Conference Publication No. 428), pp.230-235.

3 Varshney, U. (2003) 'Issues, requirements and support for location-intensive mobile commerce applications', International Journal of Mobile Communications, Vol. 1, No. 3, pp.247-263.

4 Siau, K. and Shen, Z. (2003) 'Mobile communications and mobile services', International Journal of Mobile Communications, Vol. 1, Nos. 1-2, pp.3-14.

5 Sharma, S.K., Kitchens, F.L. and Miller, P. (2003) 'A new approach for mobile comms: web services using flexible services architecture', International Journal of Mobile Communications, Vol. 1, No. 3, pp.301-311.

6 Baumann, F.V. (1999) 'MediaBuilder: a next-generation multimedia service creation and deployment platform', Bell Labs Technical Journal, April-June, Vol. 4, No. 2, pp.57-70.

7 Hussmann, H., Straten, G., Theimer, T. and Totzke, J. (1995) 'IN-based implementation of interactive video services', IEEE International Conference on Communications, Vol. 1, pp.243-249.

8 Abramowski, S., Elixmann, M., Gappisch, H., Heister, U., Heuter, U. and Klabunde, K. (1992) 'A service creation environment for intelligent networks', International Zurich Seminar on Digital Communications. Intelligent Networks and their Applications. Proceedings (Catalog No. 92TH0439-0), pp.B5/1-17.

9 Burmester, M., Koller, F. and Konig, T. (1997) 'User oriented design-PREMIERE userinterface for interactive pay-TV', Software-Ergonomie '97. Usability Engineering: Integration von Mensch-Computer-Interaktion und Software-Entwicklung (Software-Ergonomics '97. Usability Engineering: Integration of Human-Computer-Interaction and Software Development), pp.111-122.

10 Yoshimura, T., Yonemoto, Y., Ohya, T. and Etoh, M. (xxxx) 'Broadcast streaming service over cellular networks and its protocols', NTT DoCoMo Multimedia Laboratories, yoshi@spg.yrp.nttdocomo.co.jp

11 Centonza, A., Cosmas, J. and Song, Y-H. (2003) 'User behavior modeling and simulation tests for resource management in a hybrid UMTS/DVB-T Network', HYWIN 2003, International Workshop of Hybrid Wireless Networks, Turin, Italy, December 2.

12 Berg, M., Butterfield, S., Cosmas, J., Casagranda, P., Garrec, D., Guiraudou, M., Martinez, G., Launay, E., Mazieres, B. and Milanesio, D. (2003) 'CISMUNDUS: convergence of digital broadcast and mobile telecommunications', Proceedings of the IBC 2003 Conference, Amsterdam, September.

13 Arlitt, M. (1999) 'Workload characterisation of the 1998 world cup web site', Publication of Hewlett-Packard Laboratories, September 23, arlitt@hpl.hp.com

14 Ben-David, P. and Gebler, D. (2000) 'Can the web stand up to the strain?', NewsFactor Network, December 4, http://www.newsletter.com/perl/story/5658.html 